\title{
The Sense of Humor as Mediator Variable of the Relationship Self-Esteem and Happiness Among the Elderly in the Villages of Indonesia
}

\author{
Latipun Walda Isna Nisa Tulus Winarsunu \\ University of Muhammadiyah Malang, Indonesia
}

\begin{abstract}
This study aims to determine the effect of humor as a mediator of the relationship between self-esteem and happiness among elderly in Villages. The research subjects were 208 elderly aged 60-70 years in the villages of District of South Lampung, Indonesia. The instruments used were Multidimensional Sense of Humor Scale (MSHS), Self-esteem Rating Scale (SERS), and Subjective Happiness Scale (SHS). Data analysis by Mediation Regression Analysis. The results showed that the self-esteem significantly as predictor the happiness $(\beta=.21 ; p$ $=.000)$, the self-esteem also significantly as predictor the sense of humor $(\beta=.43 ; \mathrm{p}=.000)$, the humor significantly as predictor happiness $(\beta=.70 ; \mathrm{p}=.000)$. The sense humor significantly mediates on the relation the self-esteem to the happiness variable $(\beta=.30 ; \mathrm{p}=.000)$.
\end{abstract}

Keywords: Taste of humor, self-esteem, happiness, elderly, villages

DOI: $10.7176 /$ RHSS/9-6-06

Publication date:March $31^{\text {st }} 2019$

\section{Introduction}

Happiness is the desire that every individual wants to achieve for his actions (Ryff, 1989). Especially the elderly, they recognize that happiness is essential to achieve. The ancients believed that individual experience of happiness a gift of God, it was not something that was an effort by an individual (Bruni, 2010). Recent views assume that individuals are more responsible for achieving happiness (Parks, Porta, \& Pierce, 2012).

Happiness is a broad concept, like positive emotions, pleasant experiences, and has life satisfaction (Diener, Lucas, \& Oishi, 2005). Individuals are said to have happiness if they are satisfied with their living conditions, often feel positive emotions and rarely feel negative emotions. Happiness can be achieved when individuals get success for what they desire, can cultivate what strengths they have, and can feel something pleasant (Diener \& Larsen, 1984).

Many benefits of happiness for individuals, including can help in pursuing life goals, improve life welfare, and improve quality of life (Gruber, Mauss, \& Tamir, 2011). More than that, happiness also increases longevity, prevents chronic diseases (Koopmans, Geleijnse, \& Zitman, 2010), improves work quality (Judge, Ilies, \& Dimotakis, 2010), helps improve cognitive processes (Kuhbandner, Lichtenfeld, \& Pekrun, 2011), improves the ability to more creative and flexible, and sensitive to the their environment (Boehm \& Lyubomirsky, 2008).

From various researches, many factors influence happiness. They are two kinds, namely personal factors and situational factors. Personal factors that become happiness predictors include life goals achievement (Koopmans et al., 2010), emotional intelligence (Gupta, 2011), and self-esteem. While, situational factors which predicted happiness includes economic, social, marriage, culture, health, positive emotions and religion (Oishi, Kesebir, \& Diener, 2011). , Among these various factors, self-esteem as a predictor essential of achieving an individual's happiness experience, especially for the elderly. In the process of change and decline in the period of the elderly, they want to happiness in their life by protecting themselves as valuable individuals for themselves and the others.

The self-esteem for the elderly is a problem in itself. The elderly can experience change and decline the self-esteem, where the elderly often experience feelings of worthlessness and depress. In some circumstances, low self-esteem tends to cause depression. People with low self-esteem can experience unhappiness in their lives even to experience depression (Keyes, 2005).

Some elderly regard old age as a challenge and try to deal with this period for the exercise. The elderly try to compensate for physical deficits by increasing their psychological strength. They are more focused and face their live lives with optimism, hope and good self-efficacy (Seligman, 1998). They try to keep themselves useful for their environments, although on the other hand, they have experienced a reduction in their social functions.

The elderly are need self-esteem. Individuals with high self-esteem are significantly and substantially happier than those with low self-esteem. So there is a correlation between self-esteem and happiness (Baumeister, Jennifer, Joachim, \& Kathleen, 2003). This relationship is not only because of the high level of self-esteem that leads to a happy and productive life, but more than that self-esteem is also the strength for individuals to portray themselves better in their daily lives (Baumeister et al., 2003).

Self-esteem is the psychological strength of the individual. Various studies provide general conclusions that 
self-esteem can give a positive value in various lives, such as achievement behavior, productivity, and interpersonal relationships. Is self-esteem also related to humor? Some studies (e.g., Galloway, 2010; Kuiper \& McHale, 2009; Ozyesil, 2012) show that self-esteem correlated positively with a sense of humor. This result of research means that individuals with high self-esteem tend to have a high sense of humor.

Kuiper (2012) says that humor is a stimulus that can provoke laughter to someone. Humor can be jokes, funny stories, funny cartoons, embarrassing situations, and practical jokes. Humor is as one stimulus that can help someone to laugh and feel happy (Ripoll, 2010). Each has a different sense of humor according to his disposition, personality, level of attention, and intelligence.

Humor is beneficial for mental health, positive moods and zest for life (Celso Ebener, \& Burkhead, 2003). Concerning individuals, individuals tend to think more positively in seeing problems and overcoming difficulties (Lyubomirsky \& Tucker, 1998). In the context of interpersonal relationships, with humor individuals try to win the hearts of others and try to entertain others by making something fun. Conversely, individuals with a low sense of humor tend to have unfavorable social relations (Zillman \& Cantor, 1976), or individuals can have a sense of humor that allows arousing hostility by belittling others (Ruch, 1998). For those with a low sense of humor, jokes are expressed in the form of aggressive, teasing, ridicule, and insults and offensive or socially inappropriate expressions.

Humor globally is accepted as an indicator of positive mental health (Paul, Welborn, Cynthia, \& McDougal, 1986). Previous research obtained results that were in line that the sense of humor and happiness correlated positively (Paul et al., 1986). Furthermore, humor is a predictor variable of life satisfaction. Peterson, Park, and Seligman, (2006) found that individuals who had recovered from severe illnesses or psychological disorders showed increased support for character strength that contributed to increased life satisfaction. The sense of humor is one of the strengths of character as a predictor of happiness. The results of the research by Ruch, Proyer, Esser, and Mitrache (2011) concluded that the sense of humor as a strength of character correlates with happiness. Furthermore, Ruch \& Carrell (1998) also concluded that the sense of humor that can determine happiness. Even humor can be used to counteract the effects of depression (Danzer, 1990).

Happiness is positively correlated with a high sense of humor and negatively correlates with a low sense of humor. Individuals with a low sense of humor are more likely to distance themselves from others through their humor. Thus the low sense of humor reduces their happiness by reducing their social network in the face of stress (Kuiper, Melissa, Catherine, \& Gillian, 2004).

Base on the description and results of the study, the hypothesis of this research were: (1) self-esteem as predictor happiness the elderly; (2) Self-esteem as predictor sense of humor in the elderly; (3) The sense of humor as predictor happiness the elderly; and (3) The sense of humor as a mediator of the relationship between self-esteem and happiness in the elderly.

\section{Methods}

\subsection{Description of Subject}

The study subjects were 208 elderly aged 60-70 years in the district of South Lampung. They were able to communicate well and actively, listen and read well. They were visited from house to house and expressed willingness to participate in research. In detail, the demographic data of the research subjects are in Table 1.

\subsection{Instrument}

The sense of humor was measured by the Multidimensional Sense of Humor Scale instrument (MSHS; Thorson \& Powell, 1993) translated in Indonesian. The MSHS contains four statement aspects namely creativity and the use of social humor; overcome the situation of humor; attitude towards funny people; and attitude towards humor. MSHS consists of 24 items that have been validated using Principal Components Analysis with reliability $\alpha=.93$ to 12 items with the highest factor loading of $29.25 \%$ (Jose, Parreira, Thorson, \& Allwardt, 2007). MSHS is arranged in the form of a Likert scale that has a choice of answers 0 to 4 , (value $0=$ strongly disagree, value $1=$ disagree, value $2=$ neutral, value 3 = agree and value $4=$ strongly agree). The higher the score indicates the higher the sense of humor in the elderly. The reliability of MSHS on this research was $\alpha=$ .85 .

Self-esteem was measured by the instrument Self-esteem Rating Scale (SERS, Nugent \& Thomas, 1993) translated in Indonesian. SERS has several aspects that reveal about self-evaluation, social competence, problem-solving ability, intellectual ability, self-competence, and feasibility to be compared with others. SERS consists of 40 items arranged in a Likert scale format with internal consistency with $\alpha=.97$ (Nugent \& Thomas, 1993). SERS provides a clinical measure of individuals with a range of numbers 1 to 7 , $(1=$ very inappropriate, 2 = inappropriate, 3 = inappropriate, $4=$ doubtful, $5=$ quite appropriate, $6=$ appropriate, and $7=$ very appropriate). The higher the score indicates the higher of self-esteem of the elderly. The reliability of SERS on this research was $\alpha=.87$.

Table 1. Characteristics of research subjects $(\mathrm{N}=208)$ 


\begin{tabular}{|c|c|c|}
\hline Characteristics & Number & $(\%)$ \\
\hline \multicolumn{3}{|l|}{ Gender } \\
\hline Male & 103 persons & $49,5 \%$ \\
\hline Female & 105 persons & $50,5 \%$ \\
\hline \multicolumn{3}{|l|}{ Marital Status } \\
\hline Widow & 56 persons & $26,9 \%$ \\
\hline Widower & 31 persons & $14,9 \%$ \\
\hline Married & 121 persons & $58,2 \%$ \\
\hline \multicolumn{3}{|l|}{ Education } \\
\hline Primary school & 45 persons & $21,6 \%$ \\
\hline Junior high school & 61 persons & $29,3 \%$ \\
\hline Senior High School & 55 persons & $26,4 \%$ \\
\hline Bachelor & 47 persons & $22,7 \%$ \\
\hline \multicolumn{3}{|l|}{ Work } \\
\hline Farmer & 58 persons & $27,8 \%$ \\
\hline entrepreneur & 56 persons & $26,9 \%$ \\
\hline Laborer & 53 persons & $25,5 \%$ \\
\hline Retired & 41 persons & $19,8 \%$ \\
\hline \multicolumn{3}{|c|}{$\begin{array}{l}\text { Happiness was measured by the Subjective Happiness Scale (SHS; Lyubomirsky \& Lepper, 1997) } \\
\text { truments translated in Indonesian. SHS aims to assess happiness levels subjectively. SHS is arranged in the } \\
\text { m of statement questions and to answer these questions individuals are asked to circle one number between } \\
\text { mbers } 1 \text { (very low) to 7, (very high). From several research results, SHS has high internal consistency } \alpha=.81 \\
\text { yubomirsky \& Lepper, 1999) and } \alpha=.84 \text { (Damásio, Zanon \& Koller, 2014). The reliability of SHS on this } \\
\text { earch was } \alpha=.76 \text {. }\end{array}$} \\
\hline
\end{tabular}

\subsection{Data analysis}

Before data analysis is carried out, we conducted testing the classic assumption of normality, heteroscedasticity, and linearity. Base on the assumption test results, the data were normally distributed, all variables there was no indication of heteroscedasticity, the three variables were linear.

Therefore, we were using Mediation Regression Analysis for finding out whether the independent variable can explain the dependent variable and potential mediation variables which serve to mediate the relationship between predictor variables and dependent variables.

\section{Result}

\subsection{Description of Research Variables}

From the results of the correlation test between variables the study produced a significant positive correlation, namely the relationship of self-esteem with a sense of humor $(\mathrm{r}=.44 ; \mathrm{p}=.000)$, self-esteem with happiness $(\mathrm{r}=$ $.52 ; \mathrm{p}=.000)$, and sense of humor with happiness $(\mathrm{r}=.791 ; \mathrm{p}=.000)$. Table 2 is a brief description of the research variables.

Table 2. Description of relationships between variables $(n=208)$

\begin{tabular}{lcccccc}
\hline & Self-esteem & Sense of Humor & Happiness & Score Interval & Mean & $S D$ \\
\hline Self-esteem & 1 & $.44^{* * *}$ & $.52^{* * *}$ & $69-114$ & 93.07 & 12.08 \\
Sense of Humor & & 1 & $.79^{* * *}$ & $16-36$ & 27.13 & 3.67 \\
Happiness & & & 1 & $17-27$ & 21.92 & 2.14 \\
\hline
\end{tabular}

Notes: $* * * \mathrm{p}<.001)$

\subsection{Results}

Based on the results of hypothesis testing it can be concluded that self-esteem as predictor the happiness significantly $(\beta=.21 ; \mathrm{p}=.000)$. Self-Esteem contributes $15.3 \%$ to happiness. Thus it was decided that hypothesis 1 was accepted. The regression test results also showed that self-esteem as a predictor sense of humor significantly $(\beta=.44 ; p=.000)$. The self-esteem contributes $19 \%$ to the sense of humor. Thus it was decided that hypothesis 2 was accepted. The result of the analysis also indicates that the sense of humor as predictor happiness significantly $(\beta=.70 ; p=.000)$. The sense of humor contributes $51 \%$ to happiness. Thus it can be decided that hypothesis 3 is accepted. The final of the result of analysis indicates that variable the sense of humor mediate the relationship between the self-esteem and the happiness among elderly in the village (M|X $\rightarrow$ 
$\mathrm{Y}$ ), namely $\beta=.30, \mathrm{p}=.000$. Thus it was decided that hypothesis 4 was accepted. Table 3 is the result of MRA analysis, and Figure 1 is relations of variables.

Table 3. Result of Regresi Moderate Analysis $(\mathrm{n}=208)$

\begin{tabular}{llll}
\hline Independent variable & Dependent Variable & $\beta$ & $R^{2}$ \\
\hline Self-esteem & Happiness & $.21^{* * *}$ & $15,3 \%$ \\
Self-esteem & Sense of Humor & $.44^{* * *}$ & $19,0 \%$ \\
Sense of Humor & Happiness & $.70^{* * *}$ & $50,9 \%$ \\
\hline
\end{tabular}

Note: $* * * \mathrm{p}<.000)$

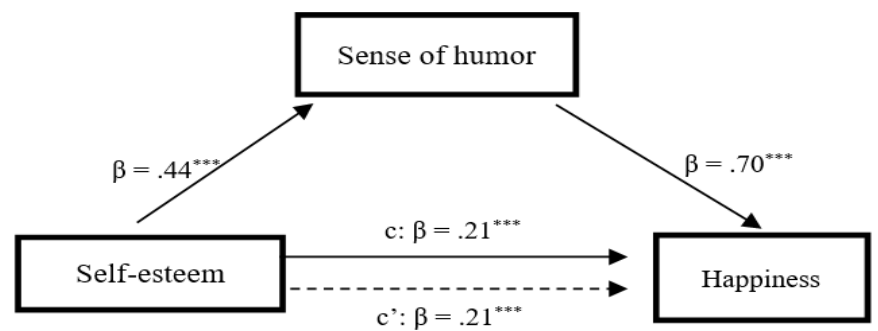

Figure 1. Relation of variables

\section{Discussion}

The results showed that positively and significantly self-esteem was predicting happiness among the elderly in the village. These results indicate that self-esteem in the elderly can increase the happiness of the elderly. This result of research consistent with the other research that self-esteem also seems to can predicting other factors such as depression. Previous research has shown that self-esteem is a significant factor in achieving happiness (Diener, 2000).

This finding is following the study by Visser (2000) who reported that self-esteem correlated with happiness. Self-esteem is so closely related to happiness that it is considered a part of happiness (Argyle \& Lu, 2002; Malik, 2013). The research is also in line with the findings of Zimmerman (2000) who has reviewed several studies and concluded that subjective well-being is related to high self-esteem and contributes to distinguishing happiness and mental well-being. Other research also found that subjective happiness is associated with high self-esteem. Furnham and Cheng (2000) find self-esteem as the primary variable that influences happiness.

The results of the research indicate there was positively and significantly influence self-esteem toward humor. Self-esteem also contributes to a sense of humor. High self-esteem in the elderly can increase the sense of humor of the elderly. This research reinforces the findings of Ozyesil (2012) which states that there is a significant correlation between self-esteem and humor and also the effect of positive-negative effect. Individuals who have negative perceptions about themselves result in low self-esteem so that the individual's sense of humor will also be low (Stieger, Formann, \& Burger, 2011). This result of research is in line with the research conducted by Kuiper and McHale (2009) which found that the level of high sense of humor was influenced significantly by self-esteem. Individuals who have high self-esteem influence the level of high sense of humor too. Research conducted by Santos and Jose (2012) also shows that individuals who have a low sense of humor have high-stress levels and who use humor more often, assess stressful situations more positively.

The other result of research also indicates that the sense of humor predicted positively and significantly on the happiness among the elderly. A sense of humor contributes to the happiness of the elderly. Previous research conducted by Paul et al. (1986) agreed that happiness and a sense of humor are positively correlated. The higher the sense of humor in the elderly, the higher the level of happiness of the elderly. This finding research is consistent with the result of research of Bharambe and Baviskar (2013) which indicated that happiness arises from a pleasant atmosphere and can be through humor as an entertaining medium and breaking the atmosphere into an interesting in everyday life.

The results also indicate that the sense of humor as a mediator of the relationship between self-esteem and happiness among the elderly. The sense of humor gives a positive influence and contributes to the relationship between self-esteem and happiness. This finding shows that the level of self-esteem also influences the level of happiness through a sense of humor as a mediator. The higher of the self-esteem of the elderly the sense of humor to be, and higher their happiness also. This research also supported the previous research conducted by Thorson, Powel, Ivan, \& William (1997) which states that a high sense of humor correlates with high selfesteem. A high sense of humor can strengthen the relationship between self-esteem and happiness. With increasing self-esteem, the level of happiness is also higher.

The research conducted by Kuiper et al. (2004) indicates that individuals with low self-esteem tend low a sense of humor, and more likely to distance themselves from others. Liu (2012) also found that a high sense of 
humor positively correlation with happiness and a low sense of humor can lead to a decrease in happiness. Cann and Etzel (2008) also prove that sense of humor as a mediator the relationship of stress with the personality (optimism, hope, and happiness).

The results of the Goldberg (2005) research also reported that humor is one of the mediators to reduce tension. So that individuals can manage emotions well and help them utilize their anger productively, namely with humor. The findings of Vuorela (2005) also found that humor can be a variable to achieve goals in improving interpersonal relationships.

\section{Conclusion}

Based on the results of the research indicated that the self-esteem and the sense of humor positively and significantly predict happiness the elderly in the villages of Indonesia. Self-esteem also positively and significantly predict the sense of humor among the elderly. The sense of humor was a mediator of the relationship between the self-esteem and the happiness of the elderly. Thus, increasing self-esteem can influence happiness among the elderly, and that influences more strength if the sense of humor as the mediated variable. The present study provides the implication that a sense of humor would promote happiness among the elderly, especially in the villages. The future calls further research primarily for the elderly in the village to consider the gender, social function, and spirituality to analysis predict happiness.

\section{References}

Argyle, M., \& Lu, L. (2002). The happiness of extroverts. Personality and Individual Differences,11, 1011 1017.

Baumeister, R. F., Jennifer, D. C., Joachim, I. K., \& Kathleen, D. V. (2003). Does high self-esteem cause better performance, interpersonal success, happiness, or healthier lifestyles? Psychological Science in the Public Interest, 4(1), 1-44.

Bharambe, K. D., \& Baviskar, P. A. (2013). A study of marital adjustment in relation to some psycho-socio factor. International Journal of Humanities and Social Science Invention, 2, 8-10

Boehm, J. K., \& Lyubomirsky, S. (2008). Does happiness promote career success? Journal of Career Assessment, 21, 134-140.

Bruni, L. (2010). The happiness of sociality. Economics and eudaimonia: A necessary encounter. Rationality and Society, 22, 383-406.

Cann, A., \& Etzel, K. C., (2008). Remembering and anticipating stressors: Positive personality mediates the relationship with sense of humor. Humor, 21, 157-178.

Celso, B. G., Ebener, D. J., \& Burkhead, E. J. (2003). Humor coping, health status, and life satisfaction among older adults residing in assisted living facilities. Aging \& Mental Health, 7(6), 438-445.

Danzer, A. (1990). Effect of exposure to humorous stimuli on induced depression. Psychol. Rep., 3, 1027-36.

Diener, E., Lucas, R. E., \& Oishi, S. (2005). Subjective well-being: The science of happiness and life satisfaction. In C. R. Snyder \& S. J. Lopez (Eds.), Handbook of positive psychology (2nd ed.), (pp. 63-73). New York, NY: Oxford University Press.

Diener, E. (2000), Subjective well-being: the science of happiness and a proposal for a national index, AmericanPsychologist, 55(1), 34-43.

Diener, E., \& Larsen, R. J. (1984). Temporal stability and cross-situational consistency of affective, behavioral, and cognitive responses. Journal of Personality and Social Psychology, 47, 871-883.

Furnham, A. \& Cheng, H. (2000). Lay theories of happiness. Journal of Happiness Studies, 1, 227-246.

Galloway, G. (2010). Individual differences in personal humor styles: Identification of prominent patterns and their associates. Personality and Individual Differences, 48, 563-567

Goldberg, S.B. (2005). The secrets of successful mediators. Negotiation Journal, 21(3), 365-376

Gruber, J., Mauss, I. B., \& Tamir, M. (2011). A dark side of happiness? How, when, and why happiness is not always good. Perspectives on Psychological Science, 6, 222-233.

Gupta, G. (2011). Emotional Intelligence and self esteem as predictor of Happiness among Professional and Non-professional students. Psychology Social, 6, 221-229.

Jose, H., Parriera, P., Thorson, J. A., \& Allwardt, D. (2007). A factor-annalistic study of the multidimensional sense of humor scale with a Portuguese sample. North American Journal of Psychology, 9(3), 595-610.

Judge, T. A., Ilies, R., \& Dimotakis, N. (2010). Are health and happiness the product of wisdom? The relationship of general mental ability to educational and occupational attainment, health, and well-being. Journal of Applied Psychology, 95, 454-468.

Keyes, C. (2005). Emotional intelligence and self esteem. Journal of consulting and clinical psychology, 73, 525 $-539$.

Koopmans, T. A., Geleijnse, J. M., \& Zitman, F. G. (2010). Effects of happiness on all-cause mortality during 15 years of follow-up: the arnhem elderly study. J Happiness Stud,11, 113-124. 
Kuhbandner, C., Lichtenfeld, S., \& Pekrun, R. (2011). Always look on the broad side of life: happiness increases the breadth of sensory memory. American Psychological Association, 11, 958-964.

Kuiper, N.A. \&McHale, N. (2009). Humor styles as mediators between self-evaluative standards and psychological well-being. The Journal of Psychology, 143(4), 359-76.

Kuiper, N.A., Melissa, G., Catherine, L., \& Gillian, K. (2004). Humor is not always the best medicine: Specific components of sense of humor and psychological well-being. Humor: International Journal of Humor Research, 17, 135-168.

Lyubomirsky, S. \&Lepper, H. (1999). A measure of subjective happiness: preliminary reliability and construct validation. Social Indicators Research, 46, 137-155.

Lyubomirsky, S. \& Tucker, K. L. (1998). Implications of individual differences in subjective happiness for perceiving, interpreting, and thinking about life events. Motivation and Emotion, 22, 155-186.

Malik, S. (2013). Gender differences in self-esteem and happiness among university students. International Journal of Development and Sustainability, 2(1), 45-454. Online www.isdsnet.com/ijds

Nugent, W.R., \& Thomas J.W. (1993). Validation of the self-esteem rating sclae. Research on Social Work Practice, 3, 191-207.

Oishi, S., Kesebir, S., \& Diener, E. (2011). Income inequality and happiness. Psychological Science, 22, 10951100.

Ozyesil, Z. (2012). The prediction level of self-esteem on humor style and positive-negative affect. Journal Psychology, 3(8), 638-641

Parks, A. C., Porta, M. D., \& Pierce, R. S. (2012). Pursuing happiness in everyday life:the characteristics and behaviors of online happiness seekers. American Psychological Association,12, 1222-1234.

Paul, N.D., Welborn, K.W., Cynthia, K.C., \& McDougal, K. (1986). Relating social interest and dogmatism to happiness and sense of humor. Individual Psychology,3(17), 421-427.

Peterson, C., Park, N., \&Seligman, M.E.P. (2006). Greater strengths of character and recovery from illness. Journal of Positive Psychology, 1(3), 17-26.

Ripoll, R. M. (2010). The therapeutic value of laughter in medicine. Narrative Review by Alternative Therapies, 16, 6-12.

Ruch, W., Proyer, R. T., Esser, C., \& Mitrache, O. (2011).Cheerfulness and everyday humorous conduct. Personality and Individual Differences, 7(2), 67-87.

Ruch, W. (1998). The Sense of Humor: Explorations of a Personality Characteristic. New York: Mouton de Gruyter.

Ruch, W., \& Carrell, A. (1998). Trait cheerfulness and the sense of humour. Personality and Individual Differences, 24(4), 551-558. doi:10.1016/S0191-8869(97)00221-3

Ryff, C. (1989). Happiness is everything or is it? Explorations on the meaning of psychological well being. Journal of personality and social psychology, 57, $1069-1081$.

Santos, M. I, \& Helena, J. (2012). Humor and health practitionaires' stress, humor contributions in stress management. International virtual conference, 1(2), 45-78. http://www.arsa-conf.com

Seligman, M.E.P. (1998). Building human strength: psychology's forgotten mission. APAMonitor, 29(1), 67-72.

Stieger, S., Formann, A. K., \&Burger, C. (2011). Humor styles and their relationship to explicit and implicit selfesteem. Personality and Individual Differences,50(5), 747-750.

Thorson, J., \& Powell, F (1993). Development and validation of a multidimensional sense of humor scale. Journal of Clinical Psychology,49, 13-23.

Thorson, J.A., Powell, F.C., Ivan, S., \&William, P.H. (1997). Psychological health and sense of humor. Journal of Clinical Psychology, 53, 605-619.

Visser, J.A. (2000), Faculty work in developing and teaching web-based distance courses: A case study of time and effort, The American Journal of Distance Education, 14(3), 21-32.

Vuorela, T. (2005). Laughing matters: A case study of humor in multi-cultural business negotiations. Negotiation Journal 21(1), 105-129

Zillman, D. \&Cantor, J.R. (1976). Dispositional theory of humor and mirth. In: A.J. Chapman \& H.C. Foot, eds. Humor and Laughter: Theory, Research, and Applications. London: Wiley, 9(2), 93-115.

Zimmerman, S.L. (2000). Self-esteem, personal control, optimism, extraversion and the subjective well-being of Midwestern university faculty. Dissertation Abstracts International B: Sciences and Engineering, 60(7), 3680 . 